\title{
DESIGN OF AN ADAPTIVE FUZZY LOGIC CONTROLLER ri IROU SLIDING MODE CONCEPT
}

$f$ areed, K. M Soliman, s. p saraya, M. F ElBaz

\begin{abstract}
This paper develops aii algonthm for designing aii adaptive fuzzy logic conti'oller based on sliding mode concept for a class of nonlinear dynamic systems for wiiich tlie plant nonjinearities is either unknown or impossible. The motivation behind tliis scheme is to combine tlie best features of fuzzy control and sliding mode to achieve rapid and accurate trackitig control. The most distinguished feature of the sliding mode is its ability to result in very robust control systems; in many cases invariant control system result against clianges in system parameters and external distiu-bances. The chatter encountered by most sliding mode control schemes is greatly alleviated without sacrificing invariant properties. The aigorithrn employs fuzzy systems to adaptively compensate for the plant nonlinearities. it is first shown iJiat tiie hizzy system with the system representative point (RP) and its derivative in variable structure conti'ol (VSC) theoiy as inputs can approximate unknown nonlinear dynamics in die neigliborhood of the switching hyperplane.

Then a new method for designing an adaptive fuzzy conti'ol system based on sliding mode is pi'oposed for the trajectoiy tracking control. Fuzzy tuning schemes are employed to improve control perfonnance and to alleviate chattering in the sliding mode. In this case, the flizzy controller acts as a compensator to refine system perfonnance. Global asymptotic stability of the algorithm- is estabhshed in the Lyapunov sense, tlie tracking eiTors converging to a neighborhood of zero. To verily the scheme, this method is aj\}plied numerically to regulate the errors in the load-Irequency control problem of an interconnected two area power generation systems connected together via a single transmission line. The results sliow that both alleviation of chatter and robust perfonnance are achieved; the advantages of the scheme are indicated in comparison with the conventional sliding mode design and demonstrate that incorporating the linguistic fuzzy information fi-om human expert's results in superior tracking perfonnance
\end{abstract}

